\title{
Glioma-Associated Antigen HEATR1 Induces Functional Cytotoxic T Lymphocytes in Patients with Glioma
}

\author{
Zhe Bao Wu, ${ }^{1,2,3}$ Chao Qiu, ${ }^{4}$ An Li Zhang, ${ }^{4}$ Lin Cai, ${ }^{2}$ \\ Shao Jian Lin, ${ }^{2}$ Yu Yao, ${ }^{1}$ Qi Sheng Tang, ${ }^{1}$ Ming Xu, ${ }^{1}$ Wei Hua, ${ }^{1}$ Yi Wei Chu, ${ }^{5}$ \\ Ying Mao, ${ }^{1}$ Jian Hong Zhu, ${ }^{1}$ Jianqing Xu, ${ }^{4}$ and Liang Fu Zhou ${ }^{1}$ \\ ${ }^{1}$ Department of Neurosurgery, Huashan Hospital, Fudan University, Shanghai 200040, China \\ ${ }^{2}$ Department of Neurosurgery, First Affiliated Hospital of Wenzhou Medical University, Wenzhou 325000, China \\ ${ }^{3}$ Department of Neurosurgery, Ruijin Hospital, Shanghai Jiao Tong University School of Medicine, Shanghai 200025, China \\ ${ }^{4}$ Key Laboratory of Medical Molecular Virology of Ministry of Education/Health at Shanghai Medical College, Shanghai Public Health \\ Clinical Center and Institutes of Biomedical Sciences, Fudan University, Jinshan District, Shanghai 200040, China \\ ${ }^{5}$ Department of Immunology and Biotherapy Research Center, Shanghai Medical College, Fudan University, Shanghai 200040, China
}

Correspondence should be addressed to Jianqing Xu; jianqingxu2008@gmail.com and Liang Fu Zhou; lfzhouc@126.com

Received 8 March 2014; Revised 17 May 2014; Accepted 16 June 2014; Published 9 July 2014

Academic Editor: Bin Zhang

Copyright (C) 2014 Zhe Bao Wu et al. This is an open access article distributed under the Creative Commons Attribution License, which permits unrestricted use, distribution, and reproduction in any medium, provided the original work is properly cited.

A2B5+ glioblastoma (GBM) cells have glioma stem-like cell (GSC) properties that are crucial to chemotherapy resistance and GBM relapse. T-cell-based antigens derived from A2B5+ GBM cells provide important information for immunotherapy. Here, we show that HEAT repeat containing 1 (HEATR1) expression in GBM tissues was significantly higher than that in control brain tissues. Furthermore, HEATR1 expression in A2B5+ U87 cells was higher than that in A2B5-U87 cells $(P=0.016)$. Six peptides of HEATR1 presented by HLA-A $* 02$ were selected for testing of their ability to induce T-cell responses in patients with GBM. When peripheral blood mononuclear cells from healthy donors $(n=6)$ and patients with glioma $(n=33)$ were stimulated with the peptide mixture, eight patients with malignant gliomas had positive reactivity with a significantly increased number of responding T-cells. The peptides HEATR $1_{682-690}$, HEATR1 $1_{126-1134}$, and HEATR $1_{757-765}$ had high affinity for binding to HLA-A $* 02: 01$ and a strong capacity to induce CTL response. CTLs against HEATR1 peptides were capable of recognizing and lysing GBM cells and GSCs. These data are the first to demonstrate that HEATR1 could induce specific CTL responses targeting both GBM cells and GSCs, implicating that HEATR1 peptide-based immunotherapy could be a novel promising strategy for treating patients with GBM.

\section{Introduction}

Human glioblastoma (GBM) accounts for approximately 60 $70 \%$ of malignant gliomas, the most common and deadly brain tumors [1]. Despite improvements in standard therapies including surgery, radiation, and chemotherapy, the poor prognosis of patients with GBM has not been obviously improved. Immunotherapy represents a promising treatment designed to reshape the immune system to specifically eradicate malignant cells. The effort of T-cell-mediated immunotherapy to selectively kill remnant glioma cells that could not be completely removed using microsurgery has been highlighted [2-4].
Glioma stem-like cells (GSCs) may be capable of initiating tumor growth $[5,6]$ and are likely to be responsible for the malignant behavior of tumors because of their acquired resistance to chemotherapy, radiotherapy, and immunotherapy induced by glioma-associated antigens, which results in the ineffectiveness of existing conventional therapies [79]. Thus, GSCs could be a novel target for cancer therapy, including immunotherapy. Our recent study findings indicated that glioma stem-like cell-associated antigens (SAAs) from CD133+ GSCs bear highly immunogenic antigens and induce significant responses from cytotoxic $\mathrm{T}$ lymphocytes (CTLs) [10]. Several other studies have tried immunotherapy targeting GSCs [11-16]. 
A2B5 is considered a marker for immature glialcommitted progenitors that are permanently generated in the subventricular zone. Glial progenitor cells are defined as cells that give rise to glial cell types such as astrocytes and oligodendrocytes. In GBM tissues, A2B5+ cells include A2B5+/CD133+ and A2B5+/CD133- cells. Furthermore, A2B5+ cells from human GBM have cancer stemlike cell properties that are crucial for the initiation and maintenance of GBM $[17,18]$. Thus, A2B5+ GBM cells could be an ideal target for GBM immunotherapy. Our recent study found that vaccination with A2B5+ GL261 cell lysate-pulsed dendritic cells had a preventive effect for mouse glioma [19]. However, T-cell epitopes derived from A2B5+ GBM progenitor cells for immunotherapy have not been reported.

To identify novel genes selectively overexpressed in $\mathrm{A} 2 \mathrm{~B} 5+\mathrm{GBM}$ as the target for T-cell mediated immunotherapy, we sequenced the mRNA profile of A2B5+ GBM cells from U87 cell lines using fluorescence-activated cell sorting (FACS) by Solexa sequencing (data not shown) and identified that the HEAT repeat containing 1 (HEATR1) gene (gene ID: 55127) was overexpressed in A2B5+ GBM cells. Recently, Bleakley et al. reported that HEATR1 was highly expressed in testis and ovary than in other tissues including liver, colon, small intestine, lung, brain, and heart [20]. Identification of epitope derived from HEATR1 is likely to provide alternative candidates for the design of antitumor vaccine with high efficacy in the future.

In the present study, we confirm the selective HEATR1 overexpression in A2B5+ GBM cells and in the vast majority of GBM. In addition, we identify several HEATR1-derived Tcell epitopes in tumor carrier patients. Our results emphasize the suitability of this protein for T-cell-based immunotherapy in patients with GBM.

\section{Materials and Methods}

2.1. Ethics Statement. The study protocol was approved by the Local Independent Ethics Committee at Huashan Hospital, Fudan University. Some samples in this study were used in our previous reports $[21,22]$. Written informed consent was obtained from each donor of the samples used in our research.

2.2. Cell Lines. Human GBM cell lines U87, A172, and SHG66 were used in this study. SHG66 came from a 47-year-old man with a right parietal glioblastoma (World Health Organization grade IV) [10]. U87 and A172 cells were purchased from the cell bank of the Shanghai Branch of Chinese Academy of Sciences. A172 cells did not express HLA-A*02:01 [23, 24], while the other two GBM cell lines expressed HLA-A $* 02: 01$ according to flow cytometry $[25,26]$. The HLA-A*02:01, expressing human tumor cells T2 (deficient in TAP1 and TAP2 transporters), and BB7.2 hybridoma, producing antiHLA-A*02 monoclonal antibody (mAb), were purchased from American Type Culture Collection (USA). All cell lines were cultured in Dulbecco's modified eagle medium (DMEM; Gibco, Grand Island, NY, USA) supplemented with $10 \%$ fetal bovine serum (FBS; Hyclone, Logan, UT, USA) and
$100 \mathrm{U} / \mathrm{mL}$ penicillin/streptomycin (Gibco) and maintained in a humidified atmosphere with $5 \% \mathrm{CO}_{2}$ at $37^{\circ} \mathrm{C}$.

The GSC lines (U87, A172, and SHG66) were established and characterized as described previously [10, 13]. Shortterm tumor spheres of the GBM cell lines were cultured in serum-free medium (SFM) consisting of DMEM/F12 (Invitrogen) supplemented with $20 \mathrm{ng} / \mathrm{mL}$ recombinant human basic fibroblast growth factor (bFGF; Chemicon), $20 \mathrm{ng} / \mathrm{mL}$ recombinant human epidermal growth factor (EGF; Chemicon), and B27 (Invitrogen). The GSC tumor spheres exhibited stem cell-like characteristics $[10,15]$.

2.3. Patients. A total of 22 frozen GBM tumor tissues were obtained from the Department of Neurosurgery, Huashan Hospital, to analyze the expression level of HEATR1 mRNA. Additionally, eight control brain tissue samples were obtained from adjacent brain tissues of patients with traumatic brain injury who suffered contusion and laceration. In addition, 10 GBM formalin-fixed, paraffin-embedded (FFPE) tissue sections and 10 normal brain tissues were analyzed by IHC.

Peripheral blood mononuclear cells (PBMCs) were isolated by Ficoll/Paque (Biochrom, Berlin, Germany) density gradient centrifugation of heparinized blood obtained from healthy donors $(n=6)$ and patients (benign tumors, 5; grade 2 astrocytoma, 7; grade 3 anaplastic glioma, 10; glioblastoma, 16). The patients' clinical characteristics are listed in Table 1.

2.4. FACS with A2B5. The U87 cells were resuspended at a density of $1 \times 10^{5}$ cells $/ \mathrm{mL}$ in SFM consisting of DMEM/F12 (Invitrogen) supplemented with $20 \mathrm{ng} / \mathrm{mL}$ recombinant human bFGF, $20 \mathrm{ng} / \mathrm{mL}$ recombinant human EGF, and B27. U87 cells were cultured for 2 weeks. A2B5PE antibody (Miltenyi Biotec) was used in this study for FACS. Cell sorting was performed on a BD FACSVantage Cell Sorter (BD Biosciences) according to the manufacturer's instructions.

2.5. Real-Time Reverse Transcription-Polymerase Chain Reaction (RT-PCR) of HEATR1 Expression. Total RNA was extracted from GBM and control brain tissues or from the GBM cell lines using Trizol reagent (Invitrogen) according to the manufacturer's instructions. First-strand cDNAs were synthesized using a High-Capacity cDNA Archive Kit. Each cDNA $(2 \mu \mathrm{L})$ was amplified in a SYBR Green Realtime PCR Master Mix (final volume, $20 \mu \mathrm{L}$ ) and loaded on an Applied Biosystems 7900 Real-time PCR Detection System (Applied Biosystems, Foster City, CA, USA). Thermal cycling conditions for quantitative RT-PCR (qRT-PCR) were as follows: the first step, $95^{\circ} \mathrm{C}$ for $10 \mathrm{~min}$ and the ensuing 40 cycles, $95^{\circ} \mathrm{C}$ for $15 \mathrm{~s}, 60^{\circ} \mathrm{C}$ for $60 \mathrm{~s}$, and $72^{\circ} \mathrm{C}$ for $30 \mathrm{~s}$. The qRT-PCR primers used were as follows: HEATR1 (forward) $5^{\prime}$-TCCTTTTTGATACCCAGCATTTTAT-3' and HEATR1 (reverse) $5^{\prime}$-TGATCCACCAGAGGCATCATC-3'; actin (forward) $5^{\prime}$-CCCTGGCACCCAGCAC- $3^{\prime}$ and actin (reverse) $5^{\prime}$-GCCGATCCACACGGAGTAC-3 ${ }^{\prime}$. All samples were analyzed in triplicate. To validate that the efficiencies of the target gene amplification and $\beta$-ACTIN amplification were approximately equal, we plotted standard curves of log input amount versus $\Delta \mathrm{CT}\left(\mathrm{CT}_{\text {target }}-\mathrm{CT}_{\text {control }}\right)$ for every 
TABLE 1: Clinical characteristics of healthy donors and patients.

\begin{tabular}{|c|c|c|c|c|c|c|c|}
\hline Number & Gender & Years & Tumor location & Pathology & Grade & ELISpot response & HLA-A2 \\
\hline 198 & M & 54 & & Healthy & & Negative & Yes \\
\hline 203 & M & 55 & & Healthy & & Negative & Yes \\
\hline 205 & $\mathrm{~F}$ & 56 & & Healthy & & Negative & Yes \\
\hline 209 & $\mathrm{~F}$ & 45 & & Healthy & & Negative & Yes \\
\hline 219 & M & 22 & & Healthy & & Negative & No \\
\hline 306 & M & 31 & & Healthy & & Negative & No \\
\hline 215 & $\mathrm{~F}$ & 48 & Right frontal & Meningioma & 0 & Negative & Yes \\
\hline 216 & $\mathrm{~F}$ & 62 & Cerebellum & Hemangioblastoma & 0 & Negative & No \\
\hline 255 & $\mathrm{~F}$ & 59 & Left frontal & Meningioma & 0 & Negative & Yes \\
\hline 226 & $\mathrm{~F}$ & 49 & Sellar region & Pituitary adenoma & 0 & Negative & Yes \\
\hline 261 & M & 21 & Sellar region & Pituitary adenoma & 0 & Negative & No \\
\hline 122 & M & 45 & Right temporal & Astrocytoma & 2 & Negative & No \\
\hline 135 & $\mathrm{~F}$ & 37 & Right temporal & Astrocytoma & 2 & Negative & Yes \\
\hline 217 & M & 48 & Right frontal & Astrocytoma & 2 & Negative & No \\
\hline 246 & $\mathrm{~F}$ & 30 & Left parietal & Astrocytoma & 2 & Negative & Yes \\
\hline 252 & M & 50 & Right temporal & Oligodendroglioma & 2 & Negative & No \\
\hline 264 & M & 45 & Right frontal-callosum & Astrocytoma & 2 & Negative & Yes \\
\hline 262 & $\mathrm{M}$ & 40 & Left temporal & Oligodendroglioma & 2 & Negative & Yes \\
\hline 218 & $\mathrm{M}$ & 58 & Right temporal & $\mathrm{AA}$ & 3 & Negative & Yes \\
\hline 238 & $\mathrm{~F}$ & 56 & Right callosal convolution & $\mathrm{AO}$ & 3 & Negative & No \\
\hline 254 & $\mathrm{~F}$ & 33 & Right frontal & $\mathrm{AOA}$ & 3 & Negative & Yes \\
\hline 256 & $\mathrm{~F}$ & 46 & Right temporal-basal ganglia & AA & 3 & Negative & No \\
\hline 259 & $\mathrm{~F}$ & 58 & Right parietal & $\mathrm{AO}$ & 3 & Negative & No \\
\hline 265 & M & 56 & Right frontal-parietal & $\mathrm{AOA}$ & 3 & Negative & No \\
\hline 127 & $\mathrm{~F}$ & 42 & Left frontal & AA & 3 & Positive & No \\
\hline 140 & M & 45 & Left temporal & AA & 3 & Positive & A0201/A1101 \\
\hline 156 & M & 48 & Left occipital & $\mathrm{AE}$ & 3 & Positive & A0203/A3001 \\
\hline 239 & M & 16 & Left temporal & AA & 3 & Positive & A0207/A1102 \\
\hline 129 & $\mathrm{~F}$ & 38 & Left occipital & GBM & 4 & Negative & Yes \\
\hline 133 & $\mathrm{~F}$ & 48 & Left temporal & GBM & 4 & Negative & No \\
\hline 147 & $\mathrm{~F}$ & 61 & Left temporal & GBM & 4 & Negative & Yes \\
\hline 150 & M & 48 & Right frontal-temporal & GBM & 4 & Negative & Yes \\
\hline 151 & M & 30 & Right temporal & GBM & 4 & Negative & Yes \\
\hline 214 & M & 66 & Right parietal-occipital & GBM & 4 & Negative & No \\
\hline 223 & M & 37 & Left frontal-temporal & GBM & 4 & Negative & Yes \\
\hline 224 & M & 59 & Left temporal-occipital & GBM & 4 & Negative & Yes \\
\hline 225 & M & 31 & Left frontal & GBM & 4 & Negative & No \\
\hline 231 & M & 36 & Left frontal & GBM & 4 & Negative & No \\
\hline 241 & M & 58 & Right frontal & GBM & 4 & Negative & Yes \\
\hline 253 & M & 54 & Left frontal & GBM & 4 & Negative & No \\
\hline 132 & M & 68 & Right temporal & GBM & 4 & Positive & A0201/A0203 \\
\hline 141 & $\mathrm{~F}$ & 12 & Right parietal-occipital & GBM & 4 & Positive & No \\
\hline 220 & $\mathrm{M}$ & 47 & Left temporal & GBM & 4 & Positive & A0201/A3303 \\
\hline 221 & $\mathrm{~F}$ & 39 & Right temporal & GBM & 4 & Positive & No \\
\hline
\end{tabular}

g: recurrence; F: female; M: male; GBM: glioblastoma multiforme; AA: anaplastic astrocytoma; AO: anaplastic oligodendroglioma; AOA: anaplastic oligoastrocytoma; AE: anaplastic ependymoma. 
gene and all the slopes of the plot $<0.1$. The $\Delta \Delta \mathrm{CT}$ method recommended by the manufacturer was used to compare the relative expression levels between samples.

2.6. IHC Analysis. Human GBM FFPE tissue sections were provided and IHC stained with HEATR1-specific antibody made against $\mathrm{COOH}$-terminal peptide of human HEATR1 (Sigma-Aldrich) using a DakoCytomation EnVision+ System-HRP (DAB) detection kit. Briefly, $5 \mu \mathrm{m}$ tissue sections were dehydrated and subjected to peroxidase blocking. HEATR1 antibody was added at a dilution of $1: 20$ and incubated at room temperature for $30 \mathrm{~min}$ on the Dako Autostainer using the DakoCytomation EnVision+ SystemHRP (DAB) detection kit. The slides were counterstained with hematoxylin. The stained slides were observed under a microscope and images were acquired. Cytoplasm staining was considered positive. To evaluate HEATR1 expression, 10 high-power fields $(400 \mathrm{x})$ within the tumor showing cytoplasm staining were selected. IHC signals were visually quantified by L.F. Sempere using a quick score system combining staining intensity and positive cell percentage (staining intensity: $0=$ negative, $1=$ weak, $2=$ intermediate, and $3=$ strong; percentage: $0=0 \%, 1=<25 \%, 2=\geq 25 \%$, and $3=\geq 50 \%$ ). All of the IHC stained sections were evaluated by two senior neuropathologists blinded to the clinical parameters.

2.7. Peptide $H L A-A * 02: 01$ Binding Affinity. The binding activity of selected peptides to the HLA-A $* 02$ molecule was determined semiquantitatively by measuring peptideinduced expression of HLA-A $* 02: 01$ on T2 cells using flow cytometry. The T2 cells were incubated for $4 \mathrm{~h}$ with the candidate peptides, respectively, at a concentration of $20 \mu \mathrm{g} / \mathrm{mL}$ in SFM. After being washed with phosphate buffered salinefetal calf serum (PBS-FCS), the T2 cells were incubated with supernatant containing murine $\mathrm{mAb}$ against HLA-A $* 02: 01$ derived from BB7.2 cells for $30 \mathrm{~min}$ at $4^{\circ} \mathrm{C}$. The T2 cells were washed twice with PBS-FCS and stained with $5 \mu \mathrm{g} / \mathrm{mL}$ diluted fluorescein isothiocyanate-conjugated immunoglobulin $\mathrm{G}$ which reacts to mouse immunoglobulin for $30 \mathrm{~min}$. The cells were then rinsed three times with PBS-FCS and analyzed using a FACSAria flow cytometer. The percent mean fluorescence index (\% MFI) increase of HLA-A $* 02: 01$ molecules was calculated as follows: $\%$ MFI increase $=[($ MFI with peptide - MFI without peptide)]/(MFI without peptide) $\times 100$ [27].

2.8. Interferon- $\gamma$ - (IFN- $\gamma$-) Based Enzyme-Linked Immunosorbent Spot (ELISpot) Assay. A human IFN- $\gamma$ ELISpot kit (552138; BD Pharmingen, CA) was used to quantify the CTL response in PBMCs. Several 96-well plates were coated with purified anti-human IFN- $\gamma$ monoclonal antibodies at the concentration of $5 \mu \mathrm{g} / \mathrm{mL}$ at $100 \mu \mathrm{L} /$ well and incubated at $4^{\circ} \mathrm{C}$ overnight and then washed once with $200 \mu \mathrm{L} /$ well of RPMI1640 containing $10 \%$ FBS and $1 \%$ penicillin-streptomycinL-glutamine (R10) and blocked with $200 \mu \mathrm{L} /$ well R10 for $2 \mathrm{~h}$ at room temperature. PBMCs were then washed twice with R10 and resuspended in R10 complete culture medium. After being counted, the cells were then adjusted to the concentration of $1 \times 10^{6}$ cells $/ \mathrm{mL}$ and plated onto a 96well ELISpot plate at $50 \mu \mathrm{L} /$ well $\left(5 \times 10^{4}\right.$ cells/well $)$ with the addition of $50 \mu \mathrm{L}$ of the peptide. The final concentration of each peptide was $5 \mu \mathrm{g} / \mathrm{mL}$. The 96-well ELISpot plates were incubated for about $20 \mathrm{~h}$ at $37^{\circ} \mathrm{C}$ in $5 \% \mathrm{CO}_{2}$. After incubation, the ELISpot plates were developed according to the kit instructions. Finally, the plates were air-dried and the resulting spots were counted with ChampSpot IV Bioreader (Beijing SAGE Creation Science, Beijing, China). Peptidespecific IFN- $\gamma$ ELISpot responses were considered positive only when the number of spots was twofold greater than the control peptide stimulation and there were $>50$ spots per $1 \times$ $10^{6}$ PBMCs $[28,29]$.

2.9. Cytotoxicity Assay by Measuring Lactate Dehydrogenase (LDH) Activity. CytoTox 96 Nonradioactive Cytotoxicity Assay (Cat. number G1780, Promega) was used to determine the cell-mediated cytotoxicity $[27,30]$. U87, SHG66, and A172 cells serving as target cells $\left(1 \times 10^{5}\right)$ were loaded with $4 \mu \mathrm{g} / \mathrm{mL}$ peptide for $2 \mathrm{~h}$ at $37^{\circ} \mathrm{C}$ and $5 \% \mathrm{CO}_{2}$. Effector PBMCs $(1 \times$ $10^{6}$ ) were added to peptide-loaded or blank target cells and cultured for additional $4 \mathrm{~h}$ at $37^{\circ} \mathrm{C}$ and $5 \% \mathrm{CO}_{2}$. To measure the $\mathrm{LDH}$ activity, $50 \mu \mathrm{L}$ of the reconstituted substrate mix was added to $50 \mu \mathrm{L}$ of the culture supernatant and incubated at room temperature protected from light for $30 \mathrm{~min}$. A total of $50 \mu \mathrm{L}$ of the stop solution was added to each well of the plate. The concentrations of the colorimetric product were recorded as absorbance at $490 \mathrm{~nm}$ by a spectrometer [27].

2.10. Statistical Analysis. All statistical analyses were carried out using the SPSS 16.0 statistical software package. Continuous variables are expressed as mean \pm SEM. Statistical differences between the two groups were evaluated using the unpaired Student's $t$-test. The correlation between ELISpot response and glioma grades was evaluated using the $\chi^{2}$ test. $P$ values $<0.05$ were considered statistically significant (twotailed test).

\section{Results}

3.1. HEATR1 Overexpression in GBM and A2B5+ GBM Cells. First, we investigated whether HEATR1 was overexpressed in GBM cells. We investigated the expression profile of HEATR1 mRNA in 22 primary GBM tissues and eight control brain tissues using quantitative RT-PCR. As shown in Figure 1(a), the expression of HEATR1 mRNA in GBM tissues was higher than that in control brain tissues $(P<0.01)$. In addition, IHC was initially performed in FFPE tissue sections of primary GBM $(n=10)$ and normal brain tissues $(n=10)$. As shown in Figure 1(b), HEATR1 protein was mainly localized in the tumor cell cytoplasm and nuclei. The average IHC score of HEATR1 expression in GBM and normal brain tissues was $4.4 \pm 0.7$ and $2.1 \pm 0.4$, respectively. GBM tissues had higher expressions of HEATR1 protein than normal brain tissues (Figure 1(c), $P=0.015)$. However, the expression level of HEATR1 proteins did not appear to be correlated with glioma grade (data not shown).

Next, we investigated whether HEATR1 expression in A2B5+GBM cells was higher than that in A2B5-GBM cells. 


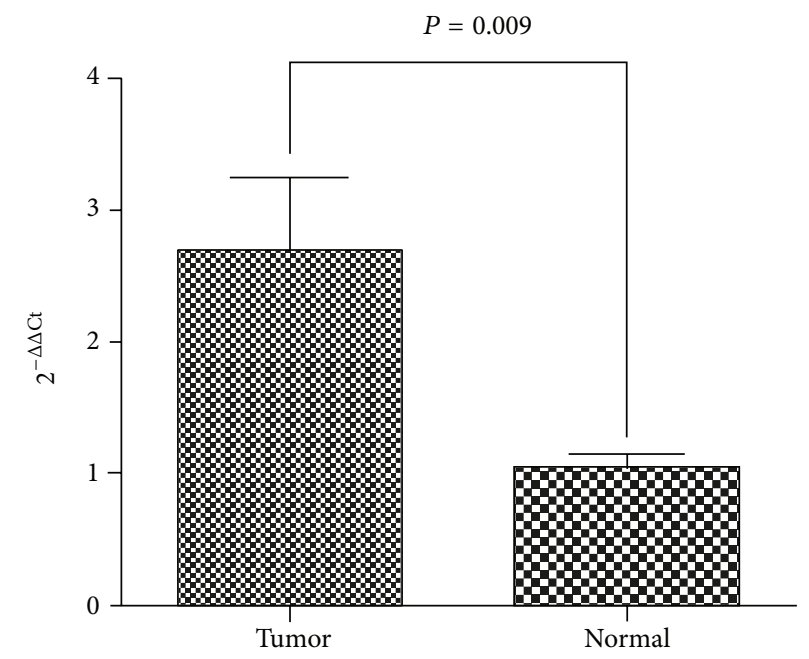

(a)
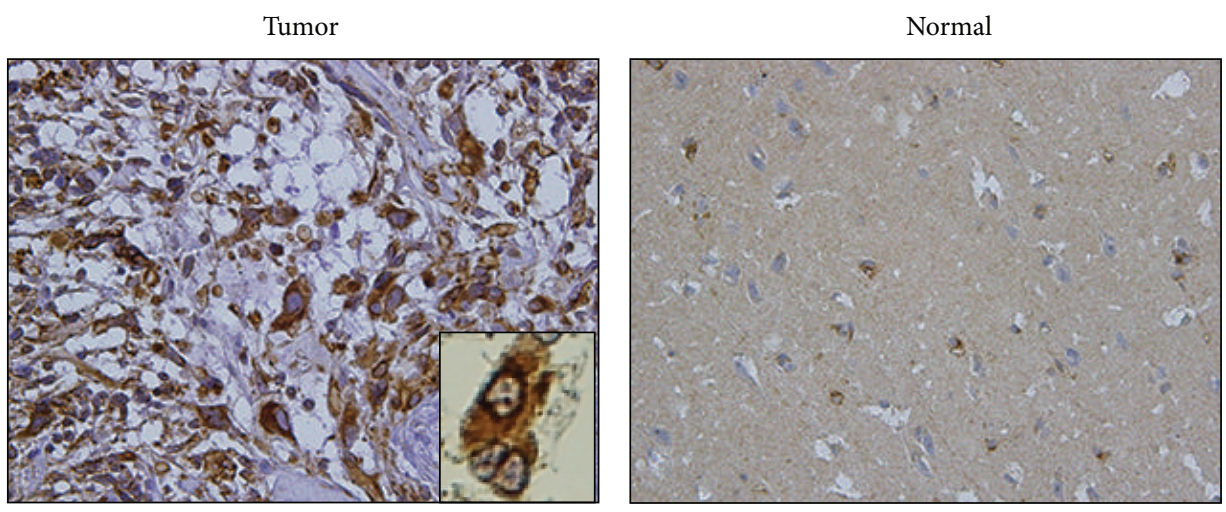

(b)

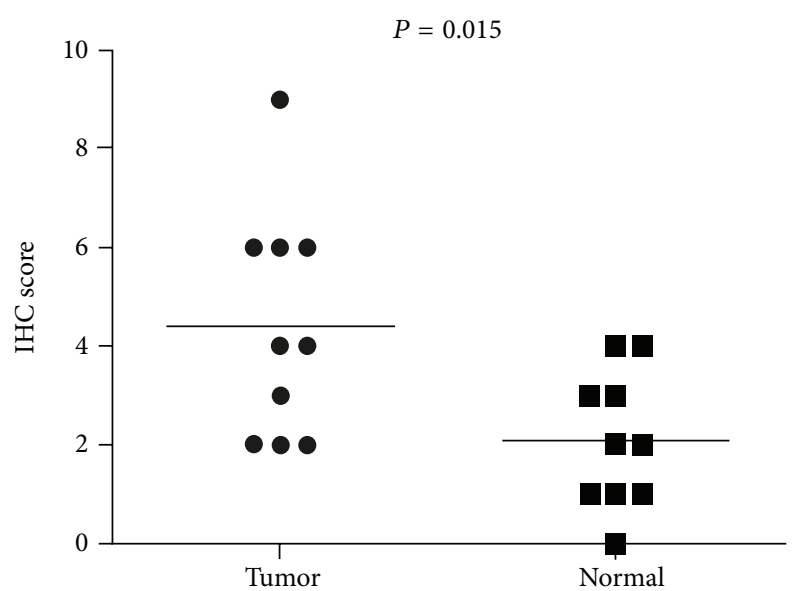

(c)

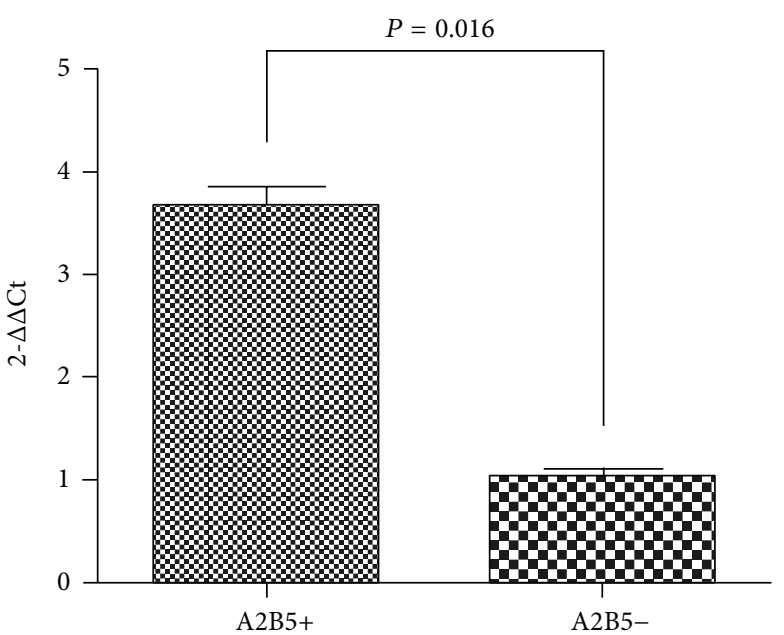

(d)

FIGURE 1: HEATR1 was overexpressed in GBM and in A2B5+GSCs. (a) qRT-PCR was performed to analyze the differential expression between GBM tissues $(n=22)$ and controlled brain tissues $(n=8)$. (b)-(c) IHC was performed in FFPE tissue sections of 10 primary GBM tissues (left, $\times 400)$ and 10 normal brain tissues (right, $\times 400)$. GBM tissues had higher staining score of HEATR1 protein than normal brain tissues $(P=0.015)$. (d) qRT-PCR was performed to analyze the differential expression between A2B5+U87 cells and A2B5-U87 cells $(P=0.0016)$. 
Our previous study showed that U87 cells cultured in SFM for 2 weeks had stem-like features [10]. Furthermore, those A2B5+ U87 cells were double-positive for CD133 and nestin or vimentin (Supplementary Figures 1, 2, and 3, resp., in the Supplementary Material available online at http://dx.doi.org/10.1155/2014/131494). Prior to sorting, the percentage of A2B5+ cells accounted for $6.5 \%$. HEATR1 mRNA in sorted A2B5+ U87 cells was significantly higher than that in A2B5-U87 cells quantified by qRT-PCR $(P=$ 0.016 , Figure $1(\mathrm{~d})$ ).

\subsection{Prediction of Candidate HLA-A*02-Binding Peptides} Derived from HEATR1. Due to HEATR1 overexpression in GBM, we sought to determine whether HEATR1derived epitopes that could be presented by antigen process machinery and induce the CTL response in patients with GBM. Since HLA-A*02:01 is expressed by $30-40 \%$ of Asians as the most common subtype of HLA-I class $[31,32]$, epitopes potentially binding to HLA-A $* 02: 01$ were generated using the HLA Peptide Binding Predictions Program (http://www-bimas.cit.nih.gov/molbio/hla_bind/) of the Bioinformatics and Molecular Analysis Section [12]. Six peptides with binding scores $>1000$ were selected as the candidate epitope peptides (Table 2). Peptides including HEATR ${ }_{2003-2011}$ (2003-2011, FLFDTQHFI), HEATR1 $1_{1126-1134}(1126-1134$, KLLRMLFDL), HEATR1 $_{2102-2110}$ (2102-2110, LLPESIPFL), HEATR1 $1_{1411-1419}$ (1411-1419, FLWILLILL), HEATR1 ${ }_{682-690}$ (682-670, KMVEDLISV), and HEATR1 $1_{757-765}$ (757-765, LMLDRGIPV) were synthesized by GL Biochem (Shanghai) Ltd. with $>95 \%$ purity as indicated by analytic high-performance liquid chromatography and mass spectrometric analysis. The negative control peptides (CFLPVFLAQPPSGQR) were also synthesized.

3.3. Affinity of Candidate Epitope Peptides for $H L A-A * 02$ Molecule. The T2-cell-peptide binding test was used to evaluate the binding affinity of these candidate epitope peptides for HLA-A*02 with flow cytometry in vitro (Figure 2(a)). As shown in Figure 2(b), HEATR1 ${ }_{682-690}$ had the highest affinity for HLA-A $* 02: 01$ and the percentage of MFI increase was $308.5 \pm 4.8 \%$. The percentages of MFI increase of HEATR $_{2102-2110}$, HEATR1 $_{1126-1134}$, and HEATR1 $1_{757-765}$ were $285.2 \pm 49.2 \%, 287.2 \pm 7.7 \%$, and $228.7 \pm 5.4 \%$, respectively. HEATR $1_{2003-2011}$ was a lower affinity peptide, while HEATR $1_{1411-1419}$ had the lowest affinity for binding to HLA$\mathrm{A} * 02$.

3.4. HEATR1-Derived Peptides Induced CTL Responses. In the next set of experiments, we tested whether those candidate peptides are epitopes that can be recognized by the host immune system in vivo. PBMCs from glioma carriers were incubated with those six mixed peptides and the IFN- $\gamma$ secretion was tested by the ELISpot. As shown in Table 1, we found that eight patients (anaplastic astrocytomas/ependymoma in four and glioblastoma in four) had positive reactivity with a significant increase of ELISpot-detected spots (Figure 3(a)). The frequency of positive reactivity in malignant gliomas

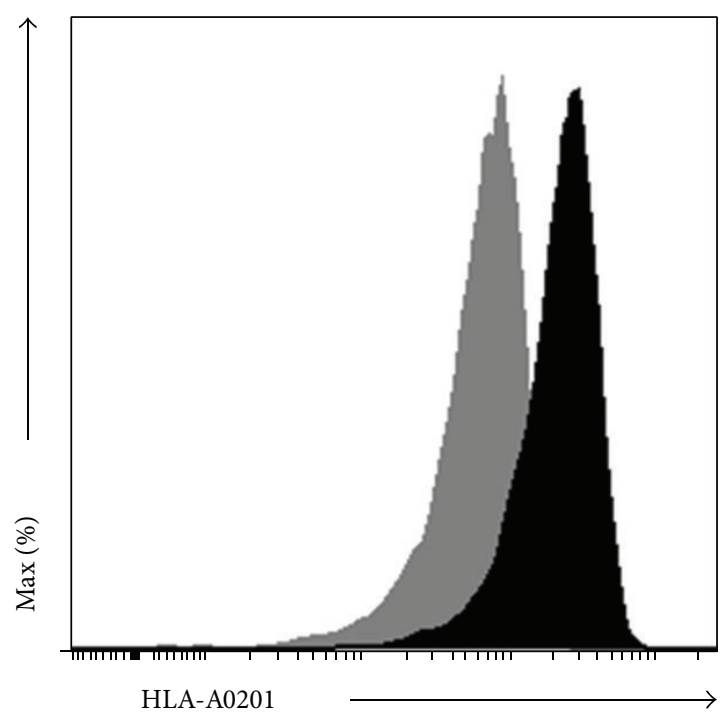

Control peptide

HEATR $1_{\text {Mix }}$

(a)

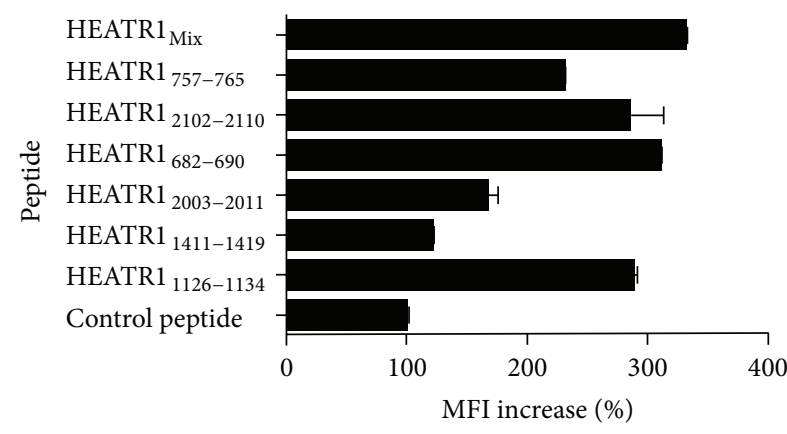

(b)

FIgURE 2: HLA-A02 binding affinity of six candidate peptides. (a) Flow cytometry results of HEATR $1_{\text {mix }}$. (b) The binding activity of selected peptides to HLA-A $* 02$ molecule was determined semiquantitatively by measuring peptide-induced expression of HLA$\mathrm{A} * 02$ on $\mathrm{T} 2$ cells with flow cytometry. Data from three independent experiments were expressed as the mean \pm SE. Unrelated 15-mer peptides were considered as control peptide.

accounts for about $31 \%$. In this study, those positive responses were only observed in the malignant glioma, indicating that those epitopes could be considered specific for malignant gliomas and significantly higher than healthy donors and low-grade glioma carriers (Figure 3(b), $P=0.022$ ). In addition, three of eight patients with positive reactivity were non-HLA-A $* 02$ (Supplementary Table 1), indicating that these peptides might not be exclusively presented by HLA$\mathrm{A} * 02$.

Furthermore, we investigated which individual HEATR1derived peptide could induce the CTL responses. PBMCs from HLA-A $* 02+$ patients, five patients with GBM and one control patient with a benign tumor, were stimulated with 


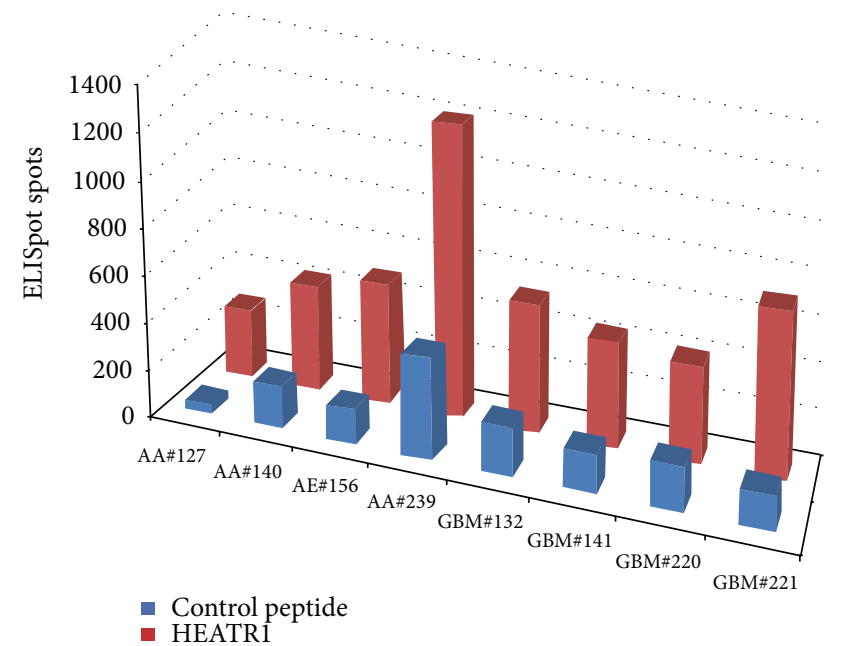

(a)

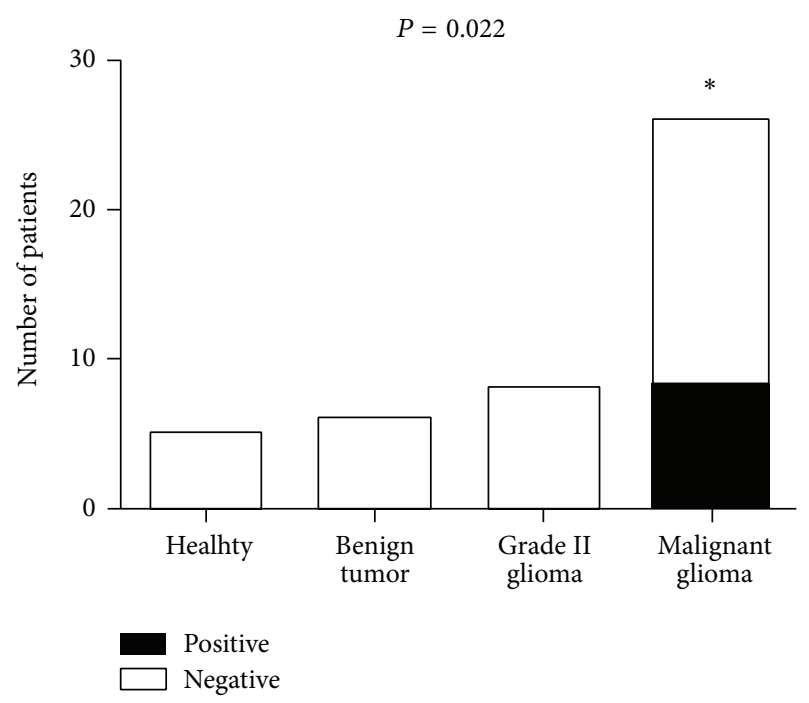

(b)

FIgURE 3: Six epitope peptides derived from the HEATR1 induce the IFN- $\gamma$ response. (a) ELISpot result of 8 malignant gliomas with positive reactivity. The number of IFN- $\gamma$ formingspots was calculated per $1 \times 10^{6}$ PBMCs. (b) The positive reactivity among 6 healthy donors and 38 patients only occurred in 8 malignant gliomas $(P=$ 0.022). GBM: glioblastoma multiforme; AA: anaplastic astrocytoma; AE: anaplastic ependymoma. This is a representative experiment from two independent experiments. No peptide stimulation was negative control. Correlation between ELISpot response and glioma grades was evaluated using a $\chi^{2}$ test.

individual peptide. As shown in Figure 4, HEATR1 $1_{757-765}$ had the highest ELISpot response, indicating that it is the most immunogenic in vivo. In addition, the ELISpot responses induced by HEATR1 ${ }_{682-690}$ and HEATR1 $1_{1126-1134}$ were higher than the others (Figure 5). These data indicate that these three peptides possess the ability to induce CTLs in vivo.

3.5. HEATR1-Specific CTLs Lyse GBM Cells and GSCs. Finally, we evaluated the ability of HEATR1-specific CTLs

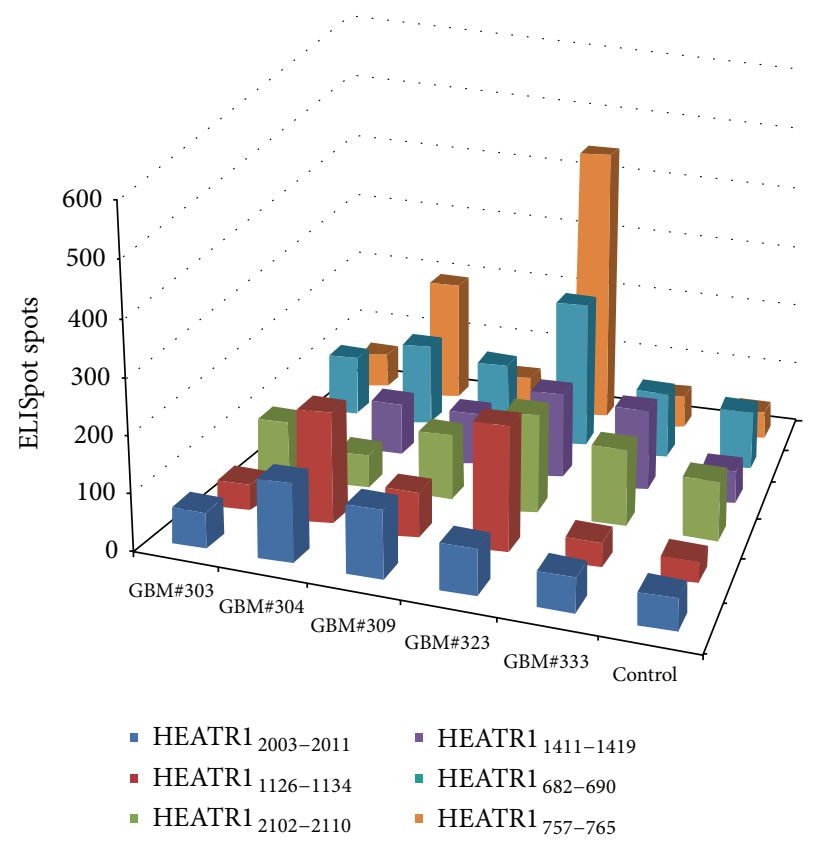

FIGURE 4: Single epitope peptide derived from the HEATR1 induces the IFN- $\gamma$ response using ELISpot assay. PBMCs were extracted from 5 patients with HLA-A2+ GBM and 1 controlled patient with HLA-A $* 02+$ benign tumor. IFN- $\gamma$ formingspots were calculated per $1 \times 10^{6}$ PBMC.

to lyse GBM cell lines endogenously expressing HEATR1 in vitro; all three GBM cell lines (U87, SHG66, and A172) are capable of expressing endogenous HEATR1 with the highest expression in U87 cell lines (Figure 5(a)). The cytotoxic activity of patients' PBMCs (effector cells) was evaluated using an LDH-release assay. PBMCs of patient 323 (positive ELISpot response with HLA-A $* 02+$; Table 1 ) were incubated with three GBM cell lines (U87, SHG66, and A172) as target cells, respectively. The results showed that peptidestimulated PBMCs could lyse $37.4 \%$ of U87 and $23.1 \%$ of SHG66 target cells expressing both HEATR1 and HLA-A $* 02$ at an E:T ratio of $10: 1$ but not A172 cells that are HLA$A * 02$-negative (Figure 5(b)). We further evaluated whether CTLs recognizing the HEATR1 peptides could kill A2B5+ GSCs. PBMCs from patient 323 demonstrated the ability to kill $76.8 \%$ of A2B5+ U87 GSCs and $20.4 \%$ of A2B5+ SHG66 GSCs at an E: T ratio of $10: 1$ (Figure 5(c)). These data suggest that HEATR1-specific CTLs are effective to lyse target cells endogenously expressing HEATR1; the cytotoxicity is associated with the expression level of endogenous HEATR1.

\section{Discussion}

To our knowledge, we reported first here that HEATR1 was especially overexpressed in GBM cells and A2B5+GBM cells. T-cell epitopes derived from HEATR1 could significantly induce the CTL response in vivo and these CTLs were able to lyse both GBM cells and GSCs. These results indicate that HEATR1 has great potential for the development of glioma immunotherapy. 

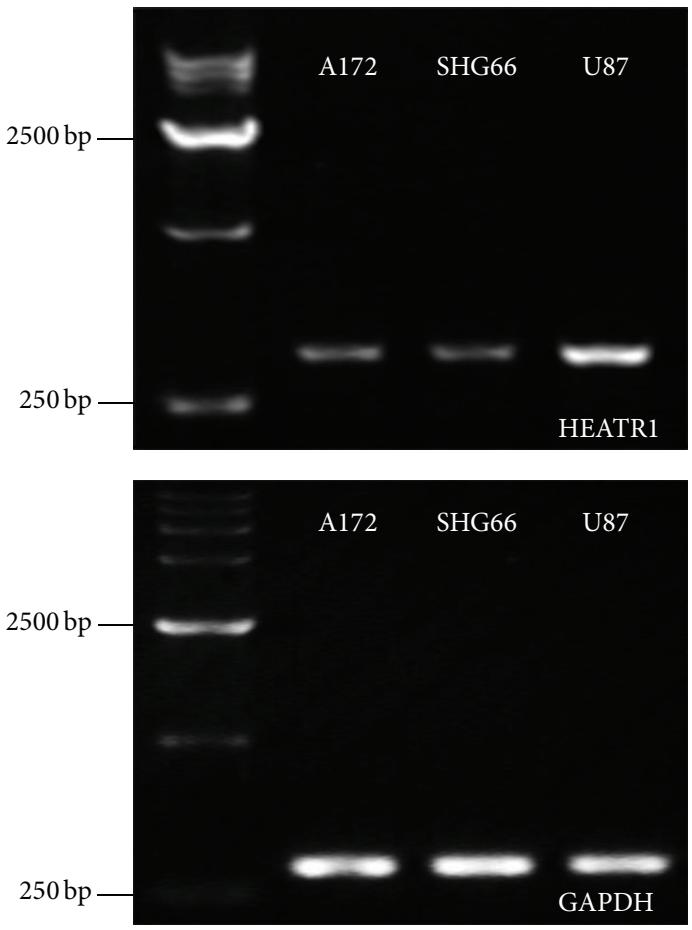

(a)

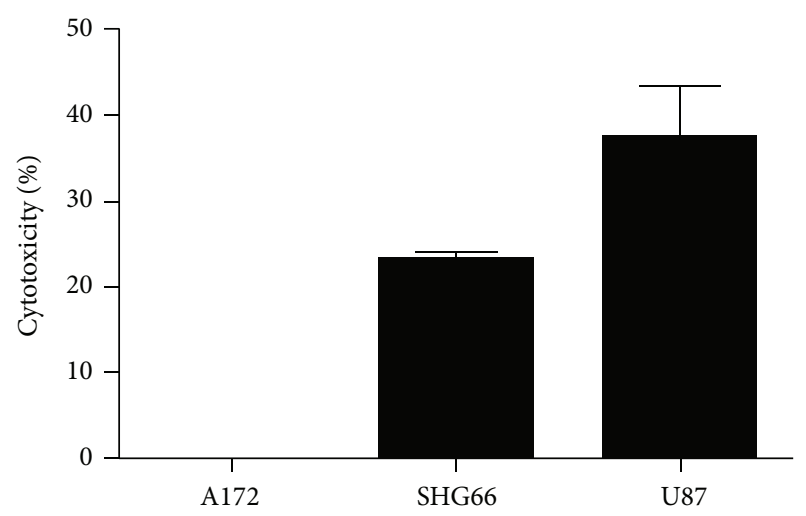

(b)

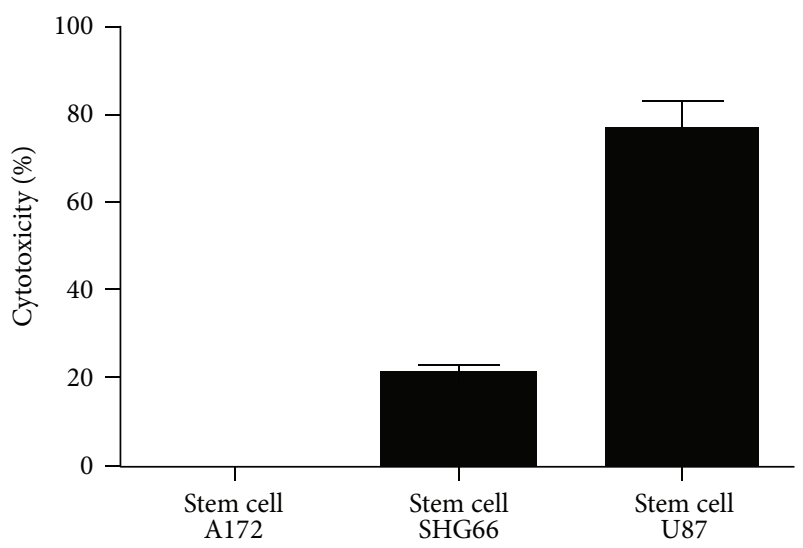

(c)

FIgURE 5: HEATR1-specific-peptide CTLs kill HLA-A*02+ gliomas that express HEATR1. (a) RNA was isolated from three GBM cell lines and mRNA expression of HEATR1 was investigated by RT-PCR. (b) The values shown represent the mean \pm SD of triplicate assays from PBMCs of patient number 323. U87, SHG66, and A172 were loaded with or without peptides and used as target cells in a LDH-release assay. The results showed that 6-peptides-stimulated PBMCs significantly lysed U87 and SHG66 target cells expressing both HEATR1 and HLA$\mathrm{A} * 02$ but not A172 cells that do not express HLA-A $* 02$ at an E/T ratio of $10: 1$. (c) Six-peptides-stimulated PBMCs from patient number 323 also significantly lysed the U87 and SHG66 GSCs at an E/T ratio of $10: 1$. Statistical differences between two groups were evaluated by the unpaired Student's $t$-test.

The HEATR1 gene is a multiple spliced $7-\mathrm{kb}$ gene that encodes bap28, a protein involved in nucleolar processing of pre-18S ribosomal RNA and ribosome biosynthesis. In the zebrafish central nervous system, bap28 is required for cell survival through its role in rRNA synthesis and processing, and its mutation leads to abnormalities in the brain starting at mid-somitogenesis stages [33]. A recent study indicated that HEATR1 is an ideal minor histocompatibility antigen that is expressed by leukemia stem cells [20,34]. Moreover, HEATR1 expression detected using TaqMan PCR was higher in testicular and ovarian tissues than in liver, colon, small intestine, lung, brain, and heart tissues [20]. In the meantime, the novel polymorphic minor histocompatibility antigen encoded by the HEATR1 gene could be recognized by one of the CTL clones. In GBM, we first confirmed that HEATR1 expression was significantly higher in most of the GBM samples than in control brain tissues. Although HEATR1 overexpression was not detected in a few cases of GBM, it might contribute to the vast genetic aberrations and their heterogeneity of GBM or GBM samples from the tumor-surrounding tissues. Furthermore, HEATR1 was overexpressed in A2B5+ GSC cells compared to A2B5-tumor cells.

To date, T-cell epitopes derived from several gliomaassociated antigens have been shown to elicit T-cell responses against gliomas of several genes, including SART-1 and 3, interleukin-13 receptor a2 chain, ARF4L, GALT3, AIM2, EphA2, EGFRvIII, HER-2, gp100, MAGE-1, glioma big potassium (gBK), TRP-2, SOX2, SOX11, SOX6, and $3^{\prime} \beta$ hydroxysteroid dehydrogenase type 7 gene $[12,24,35-50]$. Dutoit et al. recently reported that the peptidomes from ex vivo GBM samples, which consisted of 10 glioblastomaassociated antigen epitopes, induced specific tumor cell lysis by patients' CD8+ T-cells in vitro and in vivo [51]. Geet al. confirmed that gBK channel-specific peptides could induce HLA-A*02-restricted human CD8+ CTLs that killed gBK+ tumor cells [50]. In our study, we confirmed that peptide 
TABLE 2: Binding score of HEATR1-derived peptides to HLA-A02 molecules.

\begin{tabular}{|c|c|c|c|c|}
\hline Peptide & HLA molecule & Amino acid position & Subsequence residue listing & $\begin{array}{l}\text { Score (estimate of half time of } \\
\text { disassociation of a molecule } \\
\text { containing this subsequence) }\end{array}$ \\
\hline HEATR1 $_{2003-2011}$ & A_0201 & 2003-2011 & FLFDTQHFI & 4004.119 \\
\hline HEATR1 $_{1126-1134}{ }^{\&}$ & A_0201 & $1126-1134$ & KLLRMLFDL & 3690.419 \\
\hline HEATR1 $_{2102-2110}$ & A_0201 & $2102-2110$ & LLPESIPFL & 1883.533 \\
\hline HEATR1 $_{1411-1419}$ & A_0201 & $1411-1419$ & FLWILLILL & 1875.918 \\
\hline HEATR1 $_{682-670}$ & A_0201 & $682-670$ & KMVEDLISV & 1657.907 \\
\hline HEATR1 $1_{757-765}$ & A_0201 & $757-765$ & LMLDRGIPV & 1295.433 \\
\hline
\end{tabular}

${ }^{8}$ HEATR $1_{1126-1134}$ was also predicted to bind to HLA-03 and HLA-B08.

${ }^{9}$ HEATR1 $_{1411-1419}$ was also predicted to bind to HLA-B08, HLA-B40, and HLA-B3801.

epitopes derived from HEATR1 could significantly induce the CTL response of killing both GBM cells and A2B5+ GBM progenitor cells.

The CTL response in this study occurred in a non-HLA$\mathrm{A} * 02$-dependent manner. We found that HEATR1 $1_{1126-1134}$ and HEATR1 $1_{1411-1419}$ were also predicted to bind in the HLA-A $* 03$, HLA-B $* 08$, HLA-B $* 38: 01$, and HLA$\mathrm{B} * 40$ regions using the epitope prediction system of SYFPEITHI analysis database (http://www.syfpeithi.de/ bin/MHCServer.dll/EpitopePrediction.htm). Furthermore, positions 2 and 9 anchor peptides in the HLA-A*02peptide-binding groove are critical for optimal binding to HLA-A $* 02$. Positions 2 and 9 anchor peptides of those six peptides derived from HEATR1 were LL, LI, and MV, respectively (Table 2). More than 120 predicted peptides in non-HLA-A $* 02$ MHC class I (especially in HLA-B $* 08$ ) were found, where the 2nd and 9th positions were LL, LI, and MV. In addition, the HEATR1 region also was predicted to bind at least 1000 different 15 -mers to the HLA-DR regions in the SYFPEITHI analysis database that could stimulate various CD4+ T-cells. Thus, six HEATR1 peptides in this study could cross-bind to the MHC class I or MHC class II region and potentially can be used to treat patients with GBM.

Several studies have used brain tumor stem-like initiating cells or cancer stem-like cells as sources of antigens for DC vaccination against human GBM with the achievement of CSC targeting and enhancing antitumor immunity [1114]. GBM-associated tumor antigens including EGFR, HER2, TRP2, MRP3, AIM2, and SOX2 were twofold to $>200$-fold higher in CSCs than those in adherent cells [11]. Brown et al. reported that IL13-zetakine ${ }^{+}$CTLs were capable of efficient recognition and killing of both IL13R $\alpha 2^{\text {pos }}$ GSCs and IL13R $\alpha 2^{\text {pos }}$ differentiated cells in vitro and in vivo [15]. Sampson et al. reported that EGFRvIII is expressed in GSC lines and EGFRvIII chimeric antigen receptors-engineered Tcells effectively target these lines [52]. However, the number of GSC-associated proteins' peptide epitopes known to elicit T-cell responses is rather limited, and sox6 is the first protein expressed in glioma stem cells whose peptides are potentially immunogenic in patients with HLA-A $* 24$ or $-\mathrm{A} * 02$ positive glioma [12]. A2B5 is considered a marker for glioma progenitor cells and A2B5+ cells from human GBM have cancer stem cell properties that are crucial to GBM initiation and maintenance $[17,18]$. In our study, we confirmed that HEATR1-derived peptide epitopes could significantly induce the CTL response and then lyse cells from the GBMs and the GSCs, which should be considered a promising strategy for effective T-cell-based immunotherapy for patients with GBM.

HEATR1 expression in normal brain tissues was very low, unlike ARF4L and GALT3, which were markedly expressed in various normal tissues [43, 44]. Interestingly, HEATR1specific CTLs are only detectable in PBMC derived from patients with malignant gliomas but not in PBMC from healthy donors. Two reasons might account for this discrepancy. First, the induction of HEATR1-specific CTLs may require higher level of HEATR1 expression. As shown in Figure 1, HEATR1 expressions are significantly higher in tumors than in normal tissues. In other words, it is possible that the epitopes expressed in normal tissues are below the threshold level to stimulate T-cell responses [53]. Second, tumor induced microinflammation may result in the increase of permeability of blood-brain barrier and thereby help CTL to access and recognize the presented HEATR1-derived peptide on tumor cells. Furthermore, although the MAGE1, MAGE-3, Melan-A, gp100, tyrosinase, HER-2, and NYESO-1 are expressed in normal testicular, retinal, and/or brain tissues, no autoimmune responses have been elicited in the clinical trials or animal experiments of cancer vaccines [54-58]. Of course, our results require further in vivo experiments to confirm the safety and effectiveness of those HEATR1-derived epitope peptides as future immunotherapy for patients with GBM.

\section{Conclusion}

In this study, we demonstrated the selective overexpression of HEATR1 in A2B5+ GBM cells, whose epitopes could induce specific CTL responses targeting GBM cells and GSCs, suggesting that immunotherapy selectively targeting GSCs could be a novel effective strategy to treat patients with malignant glioma. Combined with other therapeutic avenues, epitope-based GSC-targeting immunotherapy may represent a new promising paradigm for the treatment of patients with GBM $[59,60]$. Moreover, those novel CTL epitopes may serve 
as an attractive component of personalized peptide-based vaccines in the treatment of GBM.

\section{Abbreviations}

$\begin{array}{ll}\text { GBM: } & \text { Glioblastoma } \\ \text { GSCs: } & \text { Gliomas stem-like cells } \\ \text { CSCs: } & \text { Cancer stem-like cells } \\ \text { FACS: } & \text { Fluorescence-activated cell sorting } \\ \text { DC: } & \text { Dendritic cell } \\ \text { HEATR1: } & \text { HEAT repeat containing 1 } \\ \text { PBMCs: } & \text { Peripheral blood mononuclear cells } \\ \text { CTL: } & \text { Cytotoxic T lymphocyte } \\ \text { Q-RT-PCR: Quantitative reverse } & \\ & \text { transcription-polymerase chain } \\ & \text { reaction } \\ \text { HLA: } & \text { Human leukocyte antigen } \\ \text { IFN: } & \text { Interferon. }\end{array}$

\section{Conflict of Interests}

The authors declare that there is no conflict of interests regarding the publication of this paper.

\section{Authors' Contribution}

Zhe Bao Wu, Chao Qiu, and An Li Zhang contributed equally to this paper.

\section{Acknowledgments}

This project was based upon work funded by Grants from Shanghai Science and Technology Research Program (13JC1408000 to Liang Fu Zhou), from the National Natural Science Foundation of China (81271523 to Zhe Bao Wu), and from Zhejiang Provincial Program for the Cultivation of High-level Innovative Health talents (Zhe Bao Wu).

\section{References}

[1] P. Y. Wen and S. Kesari, "Malignant gliomas in adults," The New England Journal of Medicine, vol. 359, no. 5, pp. 492-507, 2008.

[2] J. S. Yu, C. J. Wheeler, P. M. Zeltzer et al., "Vaccination of malignant glioma patients with peptide-pulsed dendritic cells elicits systemic cytotoxicity and intracranial T-cell infiltration," Cancer Research, vol. 61, no. 3, pp. 842-847, 2001.

[3] A. B. Heimberger and J. H. Sampson, "Immunotherapy coming of age: what will it take to make it standard of care for glioblastoma?" Neuro-Oncology, vol. 13, no. 1, pp. 3-13, 2011.

[4] Z. Li, J. Lee, D. Mukherjee et al., "Immunotherapy targeting glioma stem cells-insights and perspectives," Expert Opinion on Biological Therapy, vol. 12, no. 2, pp. 165-178, 2012.

[5] S. K. Singh, C. Hawkins, I. D. Clarke et al., "Identification of human brain tumour initiating cells," Nature, vol. 432, no. 7015, pp. 396-401, 2004.

[6] S. K. Singh, I. D. Clarke, M. Terasaki et al., "Identification of a cancer stem cell in human brain tumors," Cancer Research, vol. 63, no. 18, pp. 5821-5828, 2003.
[7] S. Bao, Q. Wu, R. E. McLendon et al., "Glioma stem cells promote radioresistance by preferential activation of the DNA damage response," Nature, vol. 444, no. 7120, pp. 756-760, 2006.

[8] D. Hambardzumyan, M. Squartro, and E. C. Holland, "Radiation resistance and stem-like cells in brain tumors," Cancer Cell, vol. 10, no. 6, pp. 454-456, 2006.

[9] A. Murat, E. Migliavacca, T. Gorlia et al., "Stem cell-related "selfrenewal" signature and high epidermal growth factor receptor expression associated with resistance to concomitant chemoradiotherapy in glioblastoma," Journal of Clinical Oncology, vol. 26, no. 18, pp. 3015-3024, 2008.

[10] W. Hua, Y. Yao, Y. Chu et al., “The CD133+ tumor stem-like cellassociated antigen may elicit highly intense immune responses against human malignant glioma," Journal of Neuro-Oncology, vol. 105, no. 2, pp. 149-157, 2011.

[11] Q. Xu, G. Liu, X. Yuan et al., "Antigen-specific T-cell response from dendritic cell vaccination using cancer stem-like cellassociated antigens," Stem Cells, vol. 27, no. 8, pp. 1734-1740, 2009.

[12] R. Ueda, K. Ohkusu-Tsukada, N. Fusaki et al., "Identification of HLA-A2- And A24-restricted T-cell epitopes derived from SOX6 expressed in glioma stem cells for immunotherapy," International Journal of Cancer, vol. 126, no. 4, pp. 919-929, 2010.

[13] C. E. Brown, R. Starr, C. Martinez et al., "Recognition and killing of brain tumor stem-like initiating cells by $\mathrm{CD}^{+}$cytolytic T cells," Cancer Research, vol. 69, no. 23, pp. 8886-8893, 2009.

[14] S. Pellegatta, P. L. Poliani, D. Corno et al., "Neurospheres enriched in cancer stem-like cells are highly effective in eliciting a dendritic cell-mediated immune response against malignant gliomas," Cancer Research, vol. 66, no. 21, pp. 10247-10252, 2006.

[15] C. E. Brown, R. Starr, B. Aguilar et al., "Stem-like tumorinitiating cells isolated from IL13R $\alpha 2$ expressing gliomas are targeted and killed by IL13-zetakine-redirected T cells," Clinical Cancer Research, vol. 18, no. 8, pp. 2199-2209, 2012.

[16] R. A. Morgan, L. A. Johnson, J. L. Davis et al., "Recognition of glioma stem cells by genetically modified $\mathrm{T}$ cells targeting EGFRvIII and development of adoptive cell therapy for glioma.," Human gene therapy, vol. 23, no. 10, pp. 1043-1053, 2012.

[17] A. Tchoghandjian, N. Baeza, C. Colin et al., "A2B5 cells from human glioblastoma have cancer stem cell properties," Brain Pathology, vol. 20, no. 1, pp. 211-221, 2010.

[18] A. T. Ogden, A. E. Waziri, R. A. Lochhead et al., "Identification of A2B5+CD133- tumor-initiating cells in adult human gliomas," Neurosurgery, vol. 62, no. 2, pp. 505-515, 2008.

[19] M. Xu, Y. Yao, W. Hua et al., "Mouse glioma immunotherapy mediated by A2B5+GL261 cell lysate-pulsed dendritic cells," Journal of Neuro-Oncology, vol. 116, pp. 497-504, 2014.

[20] M. Bleakley, B. E. Otterud, J. L. Richardt et al., "Leukemiaassociated minor histocompatibility antigen discovery using Tcell clones isolated by in vitro stimulation of naive CD ${ }^{+}$T cells," Blood, vol. 115, no. 23, pp. 4923-4933, 2010.

[21] Y. Yao, A. K. Chan, Z. Y. Qin et al., "Mutation analysis of IDH1 in paired gliomas revealed IDH1 mutation was not associated with malignant progression but predicted longer survival," PLoS ONE, vol. 8, no. 6, Article ID e67421, 2013.

[22] Z. B. Wu, L. Cai, S. J. Lin et al., "High-mobility group box 2 is associated with prognosis of glioblastoma by promoting cell viability, invasion, and chemotherapeutic resistance," NeuroOncology, vol. 15, no. 9, pp. 1264-1275, 2013.

[23] F. Okano, W. J. Storkus, W. H. Chambers, I. F. Pollack, and H. Okada, "Identification of a novel HLA-A $* 0201-$ restricted, 
cytotoxic T lymphocyte epitope in a human glioma-associated antigen, interleukin 13 receptor $\alpha 2$ chain," Clinical Cancer Research, vol. 8, pp. 2851-2855, 2002.

[24] M. Hatano, J. Eguchi, T. Tatsumi et al., "EphA2 as a gliomaassociated antigen: a novel target for glioma vaccines," Neoplasia, vol. 7, no. 8, pp. 717-722, 2005.

[25] R. Somasundaram, L. Caputo, D. P. Guerry, and D. Herlyn, "CD8 ${ }^{+}$, HLA-unrestricted, cytotoxic T-lymphocyte line against malignant melanoma," Journal of Translational Medicine, vol. 3, article 41, 2005.

[26] G. Z. Jian, J. Eguchi, C. A. Kruse et al., "Antigenic profiling of glioma cells to generate allogeneic vaccines or dendritic cellbased therapeutics," Clinical Cancer Research, vol. 13, no. 2, pp. 566-575, 2007.

[27] Z. C. Jia, B. Ni, Z. M. Huang et al., "Identification of two novel HLA-A *0201-restricted CTL epitopes derived from MAGEA4," Clinical \& Developmental Immunology, vol. 2010, Article ID 567594, 2010.

[28] A. Bredenbeck, F. O. Losch, T. Sharav et al., "Identification of noncanonical melanoma-associated $\mathrm{T}$ cell epitopes for cancer immunotherapy," Journal of Immunology, vol. 174, no. 11, pp. 6716-6724, 2005.

[29] T. Hakamada, K. Funatsuki, H. Morita et al., "Identification of novel hepatitis $\mathrm{C}$ virus-specific cytotoxic T lymphocyte epitopes by ELISpot assay using peptides with human leukocyte antigenA*2402-binding motifs," The Journal of General Virology, vol. 85, no. 6, pp. 1521-1531, 2004.

[30] M. L. Shinohara, M. Jansson, E. S. Hwang, M. B. F. Werneck, L. H. Glimcher, and H. Cantor, "T-bet-dependent expression of osteopontin contributes to T cell polarization," Proceedings of the National Academy of Sciences of the United States of America, vol. 102, no. 47, pp. 17101-17106, 2005.

[31] M. T. Duffour, P. Chaux, C. Lurquin, G. Cornelis, T. Boon, and P. van der Bruggen, "A MAGE-A4 peptide presented by HLAA2 is recognized by cytolytic T lymphocytes," European Journal of Immunology, vol. 29, pp. 3329-3337, 1999.

[32] B. Liang, L. Zhu, Z. Liang et al., "A simplified PCR-SSP method for HLA-A2 subtype in a population of Wuhan, China," Cellular \& Molecular Immunology, vol. 3, no. 6, pp. 453-458, 2006.

[33] M. Azuma, R. Toyama, E. Laver, and I. B. Dawid, "Perturbation of rRNA synthesis in the bap28 mutation leads to apoptosis mediated by p53 in the zebrafish central nervous system," Journal of Biological Chemistry, vol. 281, no. 19, pp. 13309-13316, 2006.

[34] A. J. Barrett and J. J. Melenhorst, "Minor histocompatibility antigen discovery: turning up the HEATR," Blood, vol. 115, no. 23, pp. 4630-4631, 2010.

[35] C. E. Myers, P. Hanavan, K. Antwi et al., "CTL recognition of a novel HLA-A $* 0201$-binding peptide derived from glioblastoma multiforme tumor cells," Cancer Immunology, Immunotherapy, vol. 60, no. 9, pp. 1319-1332, 2011.

[36] M. Schmitz, A. Temme, V. Senner et al., "Identification of SOX2 as a novel glioma-associated antigen and potential target for $\mathrm{T}$ cell-based immunotherapy," British Journal of Cancer, vol. 96, no. 8, pp. 1293-1301, 2007.

[37] G. Liu, H. Ying, G. Zeng, C. J. Wheeler, K. L. Black, and J. S. Yu, "HER-2, gp100, and MAGE-1 are expressed in human glioblastoma and recognized by cytotoxic T cells," Cancer Research, vol. 64, no. 14, pp. 4980-4986, 2004.

[38] S. Shimato, A. Natsume, T. Wakabayashi et al., "Identification of a human leukocyte antigen-A24-restricted T-cell epitope derived from interleukin-13 receptor alpha2 chain, a gliomaassociated antigen: laboratory investigation," Journal of Neurosurgery, vol. 109, no. 1, pp. 117-122, 2008.

[39] K. Kawakami, M. Terabe, M. Kawakami, J. A. Berzofsky, and R. K. Puri, "Characterization of a novel human tumor antigen interleukin-13 receptor $\alpha 2$ chain," Cancer Research, vol. 66, no. 8, pp. 4434-4442, 2006.

[40] I. O. Sullivan, M. Blaszczyk-Thurin, C. T. Shen, and H. C. J. Ertl, "A DNA vaccine expressing tyrosinase-related protein2 induces T-cell-mediated protection against mouse glioblastoma," Cancer Gene Therapy, vol. 10, no. 9, pp. 678-688, 2003.

[41] T. Imaizumi, T. Kuramoto, K. Matsunaga et al., "Expression of the tumor-rejection antigen SART1 in brain tumors," International Journal of Cancer, vol. 83, pp. 760-764, 1999.

[42] K. Murayama, T. Kobayashi, T. Imaizumi et al., "Expression of the SART3 tumor-rejection antigen in brain tumors and induction of cytotoxic T lymphocytes by its peptides," Journal of Immunotherapy, vol. 23, no. 5, pp. 511-518, 2000.

[43] Y. Nonaka, N. Tsuda, S. Shichijo et al., "Recognition of ADPribosylation factor 4-like by HLA-A2-restricted and tumorreactive cytotoxic $\mathrm{T}$ lymphocytes from patients with brain tumors," Tissue Antigens, vol. 60, no. 4, pp. 319-327, 2002.

[44] N. Tsuda, Y. Nonaka, S. Shichijo et al., "UDP-Gal: $\beta$ GlcNAc $\beta 1$, 3-galactosyltransferase, polypeptide 3 (GALT3) is a tumour antigen recognised by HLA-A2-restricted cytotoxic T lymphocytes from patients with brain tumour," British Journal of Cancer, vol. 87, no. 9, pp. 1006-1012, 2002.

[45] G. Liu, J. S. Yu, G. Zeng et al., "AIM-2: a novel tumor antigen is expressed and presented by human glioma cells," Journal of Immunotherapy, vol. 27, no. 3, pp. 220-226, 2004.

[46] A. Wu, J. Xiao, L. Anker et al., "Identification of EGFRvIIIderived CTL epitopes estricted by HLA A0201 for dendritic cell based immunotherapy of gliomas," Journal of Neuro-Oncology, vol. 76, no. 1, pp. 23-30, 2006.

[47] M. Schmitz, R. Wehner, S. Stevanovic et al., "Identification of a naturally processed $\mathrm{T}$ cell epitope derived from the gliomaassociated protein SOX11," Cancer Letters, vol. 245, no. 1-2, pp. 331-336, 2007.

[48] H. T. Khong and S. A. Rosenberg, "Pre-existing immunity to tyrosinase-related protein (TRP)-2, a new TRP-2 isoform, and the NY-ESO-1 melanoma antigen in a patient with a dramatic response to immunotherapy," Journal of Immunology, vol. 168, no. 2, pp. 951-956, 2002.

[49] G. Liu, H. T. Khong, C. J. Wheeler, J. S. Yu, K. L. Black, and H. Ying, "Molecular and functional analysis of tyrosinase-related protein (TRP)-2 as a cytotoxic T lymphocyte target in patients with malignant glioma," Journal of Immunotherapy, vol. 26, no. 4, pp. 301-312, 2003.

[50] L. Ge, N. T. Hoa, A. N. Cornforth et al., "Glioma big potassium channel expression in human cancers and possible $\mathrm{T}$ cell epitopes for their immunotherapy," Journal of Immunology, vol. 189, no. 5, pp. 2625-2634, 2012.

[51] V. Dutoit, C. Herold-Mende, N. Hilf et al., "Exploiting the glioblastoma peptidome to discover novel tumour-associated antigens for immunotherapy," Brain, vol. 135, no. 4, pp. 10421054, 2012.

[52] J. H. Sampson, G. E. Archer, D. A. Mitchell, A. B. Heimberger, and D. D. Bigner, "Tumor-specific immunotherapy targeting the EGFRvIII mutation in patients with malignant glioma," Seminars in Immunology, vol. 20, no. 5, pp. 267-275, 2008. 
[53] N. Renkvist, C. Castelli, P. F. Robbins, and G. Parmiani, "A listing of human tumor antigens recognized by T cells," Cancer Immunology, Immunotherapy, vol. 50, no. 1, pp. 3-15, 2001.

[54] X. Hu, N. G. Chakraborty, J. R. Sporn, S. H. Kurtzman, M. T. Ergin, and B. Mukherji, "Enhancement of cytolytic T lymphocyte precursor frequency in melanoma patients following immunization with the MAGE-1 peptide loaded antigen presenting cell-based vaccine," Cancer Research, vol. 56, no. 11, pp. 2479-2483, 1996.

[55] M. Marchand, N. van Baren, P. Weynants et al., "Tumor regressions observed in patients with metastatic melanoma treated with an antigenic peptide encoded by gene MAGE- 3 and presented by HLA-A1," International Journal of Cancer, vol. 80, no. 2, pp. 219-230, 1999.

[56] B. Thurner, I. Haendle, C. Röder et al., "Vaccination with Mage3A1 peptide-pulsed nature, monocyte-derived dendritic cells expands specific cytotoxic $\mathrm{T}$ cells and induces regression of some metastases in advanced stage IV melanoma," The Journal of Experimental Medicine, vol. 190, no. 11, pp. 1669-1678, 1999.

[57] A. Mackensen, B. Herbst, J. Chen et al., "Phase I study in melanoma patients of a vaccine with peptide-pulsed dendritic cells generated in vitro from $\mathrm{CD} 34^{+}$hematopoietic progenitor cells," International Journal of Cancer, vol. 86, no. 2, pp. 385-392, 2000.

[58] R. M. Prins, S. K. Odesa, and L. M. Liau, "Immunotherapeutic targeting of shared melanoma-associated antigens in a murine glioma model," Cancer Research, vol. 63, no. 23, pp. 8487-8491, 2003.

[59] S. Phuphanich, C. J. Wheeler, J. D. Rudnick et al., "Phase i trial of a multi-epitope-pulsed dendritic cell vaccine for patients with newly diagnosed glioblastoma," Cancer Immunology, Immunotherapy: CII, vol. 62, no. 1, pp. 125-135, 2013.

[60] J. H. Sampson, A. B. Heimberger, G. E. Archer et al., "Immunologic escape after prolonged progression-free survival with epidermal growth factor receptor variant III peptide vaccination in patients with newly diagnosed glioblastoma," Journal of Clinical Oncology, vol. 28, no. 31, pp. 4722-4729, 2010. 


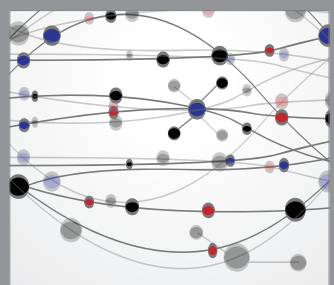

The Scientific World Journal
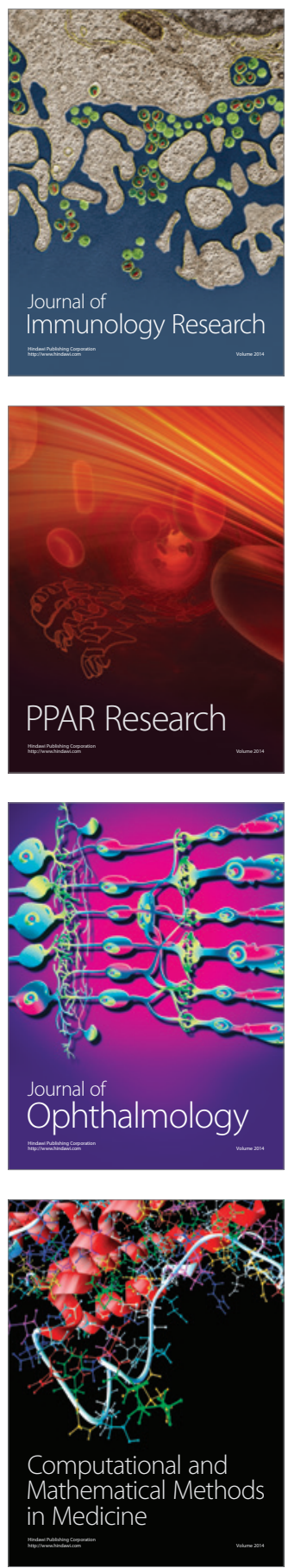

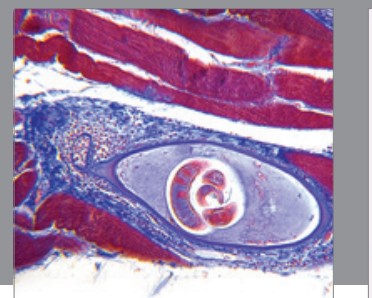

Gastroenterology

Research and Practice
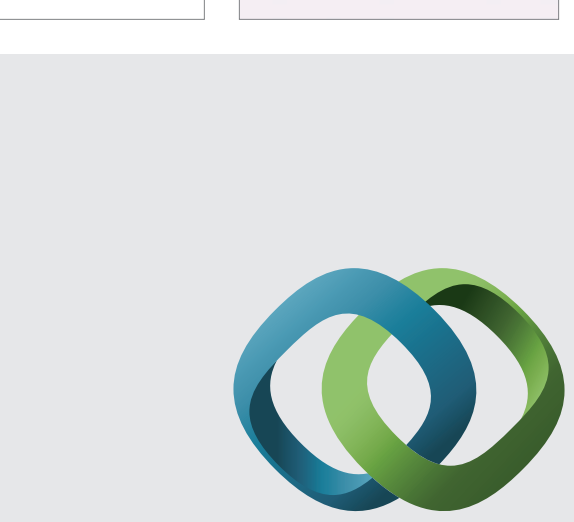

\section{Hindawi}

Submit your manuscripts at

http://www.hindawi.com
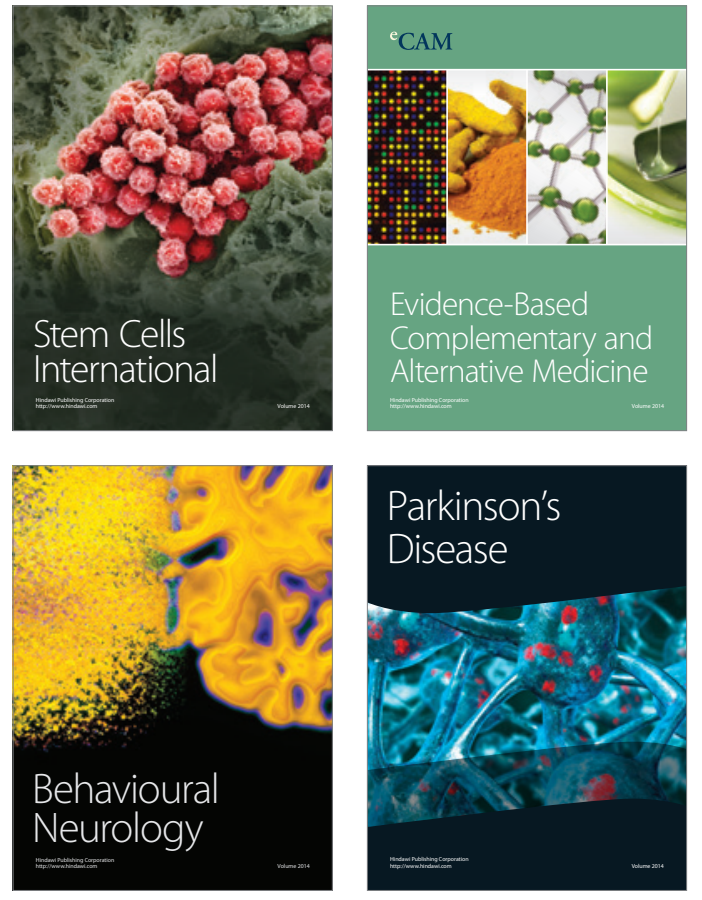
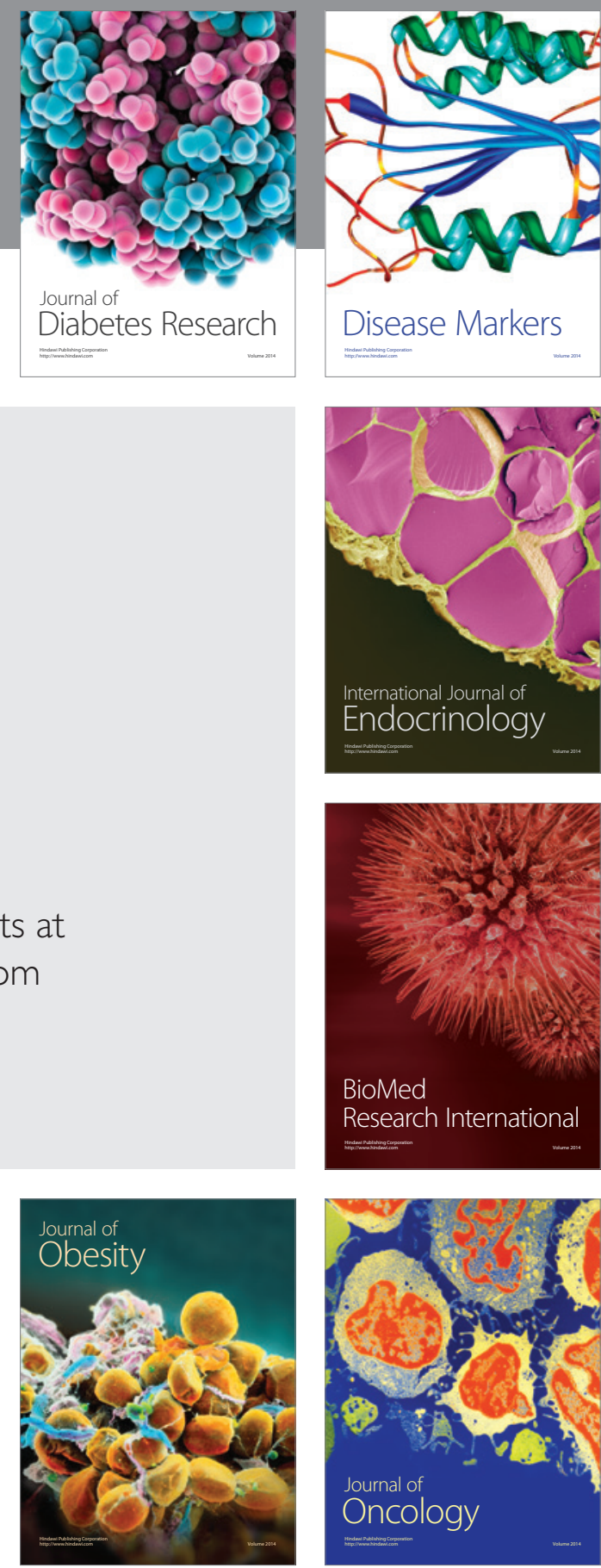

Disease Markers
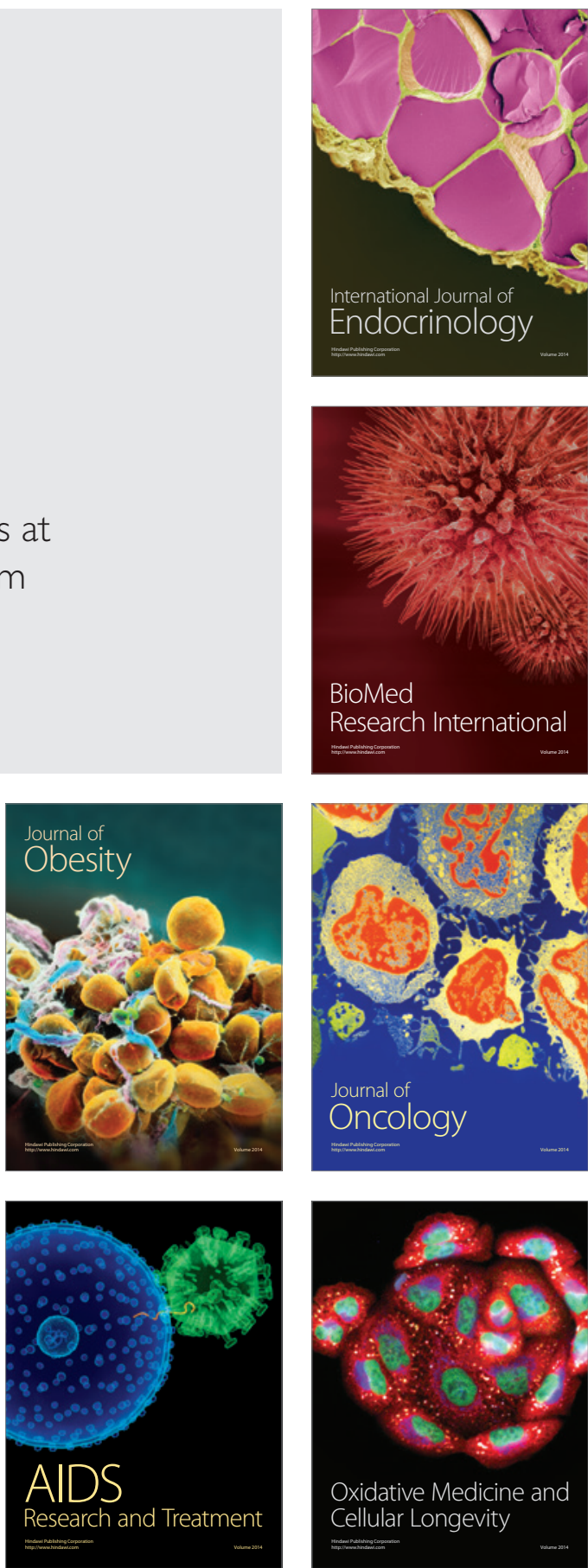